\title{
A DEMOCRACIA NECESSÁRIA, SEGUNDO FRANCISCO WEFFORT
}

Um dos mistérios e, ao mesmo tempo, encantamentos da democracia é perceber que se trata, ao fim e ao cabo, de um sistema político extremamente frágil e que por essa razão precisa ser cuidado e preservado. No fundo, tudo se baseia na crença de que os derrotados nas eleições vão aceitar pacificamente o resultado das urnas e aguardar a próxima disputa eleitoral para tentar fazer prevalecer os seus argumentos. Estamos acostumados a olhar para os candidatos vencedores, quando, para compreender o funcionamento do sistema, é preciso olhar também e sobretudo para os perdedores. Caso se sintam excluídos do processo todo, há sempre a possibilidade de não aceitarem o resultado e clamarem por fraudes eleitorais, colocando em perigo a sobrevivência do sistema democrático. Em outras palavras, uma democracia somente se sustenta se puder contar com o consentimento dos perdedores, título de um livro publicado em 2005, em que os autores sustentam a comparação de que os cientistas políticos são como treinadores de times de futebol, prestam mais atenção aos vencedores do que aos perdedores, frequentemente esquecidos.

"No entanto," alertam, "por mais interessantes e emocionantes que sejam os vencedores e suas vitórias, eles representam apenas um lado da moeda quando se trata de compreender a vida política. Na verdade, afirmamos que compreender a vitória não é mais relevante do que compreender os derrotados no que diz respeito ao estudo dos sistemas políticos, dado que as atitudes e comportamentos dos perdedores determinam se o jogo não será interrompido, em primeiro lugar, e se continuará a ser jogado no longo prazo." (Anderson et al., 2005, p. 2, tradução minha) 
Na perspectiva dos autores, o comportamento dos perdedores é crucial para a consolidação de sistemas democráticos estáveis e legítimos, daí a ênfase dada à maneira como as instituições condicionam as derrotas eleitorais, como os perdedores respondem às derrotas, e como o "consentimento dos perdedores" afeta a legitimidade e a viabilidade das instituições democráticas.

Neste momento, a sociedade brasileira parece estar dividida, de um lado estão aqueles que confiam nas instituições democráticas e na capacidade do sistema eleitoral de canalizar as escolhas dos cidadãos, e do outro lado estão os indivíduos que desafiam a legitimidade das instituições, contestam a credibilidade das urnas eletrônicas, pregam a volta do voto impresso, insuflam seus seguidores contra o Supremo Tribunal Federal, atacam os direitos humanos e desejam a instituição de um regime militar. Várias das questões tratadas nos artigos publicados neste número estão na ordem do dia.

A bem da verdade, a reflexão sobre a democracia esteve sempre presente na revista Lua Nova, como atesta esse trecho do editorial publicado no número 21, de outubro 1990:

Como de hábito nas páginas de Lua Nova, a preocupação maior de todos é a democracia. E o grande problema que temos pela frente é o de encontrar as condições que permitam a consolidação da democracia, o que significa encontrar as condições que permitam à democracia sobreviver à crise econômica. São estes os termos de um debate que, na verdade, apenas se inicia e que promete durar, nos diferentes cenários da cultura e da política dos nossos países, até que a América Latina reencontre os caminhos da modernidade. (Weffort, 1990, p. 3)

Seu autor, Francisco Weffort, fundador e primeiro diretorpresidente do CEDEC, professor titular de Ciência Política 
da Universidade de São Paulo (USP), e editor de Lua Nova, nos deixou no dia 2 de agosto de 2021. Sua contribuição para a revista foi importante e pode ser lida nos arquivos da revista no SciELO ou na página do CEDEC. Já no segundo número de Lua Nova, publicado em 1984, Francisco Weffort fazia uma reflexão sobre as diferenças e pontos comuns entre jornais e partidos políticos e chamava a atenção para a necessidade de conjugar a opinião com a ação:

Jornais não são partidos políticos. Mas como se parecem às vezes! Nos embates que precedem o golpe de 1964, o Estadão desempenhou algumas das funções essenciais de um partido. Hoje, a Folha funciona, pelo menos na campanha das diretas, como se fosse uma frente política. Em 1964, o Estadão estava ligado, embora apenas por vínculos de amizade e de opção pessoal de alguns dos seus diretores, à União Democrática Nacional (UDN). No caso da Folha, as ligações partidárias são ainda mais tênues. E, contudo, ela aparece como uma frente, ou pelo menos parte de uma frente. De uma frente política que, aliás, pelo menos formalmente, não existe.

Bem pensadas as coisas, não deveria haver problema nenhum se um jornal liberal se parece com um partido ou com uma frente. A tradição liberal gosta de definir os partidos como partidos de opinião. E que dizer da tradição da imprensa moderna senão que enraíza, também, no prestígio da opinião? Em que pese o desenvolvimento recente do chamado jornalismo objetivo, apoiado sobretudo na força da informação, não se conseguiu desbancar a tradição. As páginas editoriais dos jornais continuam sendo o espaço nobre dos jornais e a opinião flui, de modo explícito ou não, em todo o noticiário. Se os partidos são de opinião e os jornais também são de opinião, nada de surpreendente se estes às vezes se comportam como aqueles. (Weffort, 1984, p. 37) 
Homem de partido e de ação, depois de ter sido fundador e membro da Executiva Nacional do Partido dos Trabalhadores, foi ministro da Cultura no governo de Fernando Henrique Cardoso. Francisco Weffort não podia conceber a reflexão sobre a ciência política como algo abstrato, desligado da experiência histórica e da sua época:

O fato de que comecemos por algumas referências conceituais abstratas não deve induzir ninguém a imaginar, temerosamente, que os dilemas da legitimidade política nos obriguem a todos a caminhar pela estratosfera. Não, pelo menos não o tempo todo. A verdade é que quando se fala de legitimidade política se fala também, e principalmente, de fatos muito reais e muito dramáticos de uma época histórica. Precisamente esta em que nos foi dado viver. (Weffort, 1988, p. 8)

Essa experiência histórica e o conhecimento das lutas políticas explicam por que Francisco Weffort sabia das dificuldades da realização da democracia no Brasil:

Mais importante é assinalar que, assim como a modernidade não está assegurada para nenhum dos nossos países, a democracia não é, evidentemente, a única possibilidade desta época de crise em nossa história. Assim como o estancamento econômico empurra muitas partes da América Latina para a desagregação e para a degenerescência, existem também possibilidades de regressão ao autoritarismo e mesmo possibilidades que, se não são de regressão, são de coisa ainda pior do que tudo que já vimos até aqui. Mas mesmo que se tenha que reconhecer como uma ingenuidade acreditar que a democracia esteja assegurada por qualquer lei inelutável da história e, além disso, mesmo que se reconheça que possam existir outros caminhos para recolocar a América 
Latina no caminho do desenvolvimento econômico, não creio que se possa negar que a democracia é o único caminho que pode levar os países latino-americanos à modernidade. (Weffort, 1990, p. 39)

Passadas quatro décadas, somos forçados a admitir que o texto permanece assustadoramente atual ao alertar contra possibilidades de regressão ao autoritarismo ou a "coisa pior do que tudo que já vimos até aqui”. Sobretudo quando as ameaças partem dos que deveriam ser os maiores fiadores da democracia, como afirma Weffort ao destacar o papel das lideranças para a garantia da estabilidade democrática:

As novas democracias, quando ainda não consolidadas, são politicamente instáveis e institucionalmente frágeis. Mas quando estudamos, em conjunto, democracias que falharam, as diferenças entre democracias "velhas" e "novas" aparecem sob uma luz diferente. Estes estudos nos lembram que isso que os cientistas políticos chamam de estabilidade e solidez institucional implica, de fato, uma preocupação permanente dos líderes com o aperfeiçoamento dos processos democráticos. É certo que em algumas democracias consolidadas, o entusiasmo democrático das lideranças é, às vezes, substituído pelo simples automatismo e por hábitos mais ou menos mecânicos. Mas o funcionamento da democracia desenvolve também seus próprios antídotos contra tais males gerados pela estabilidade e pela acomodação. Antídotos, que, uma vez mais, ressaltam o papel das lideranças. (Weffort, 1992, p. 7-8)

Para seguir nessa tradição de pensar a democracia é que apresentamos aqui artigos que retomam as temáticas da democracia e da reivindicação de direitos. No primeiro artigo, "Do povo, para o povo e pelo povo: origem e exercício da soberania na teoria política contemporânea", 
Gabriela Rodrigues da Guia Rosa discute as influências do conceito de soberania popular formulado por Rousseau na teoria política contemporânea. Se, como argumenta a autora, democracia e soberania do povo não estão necessariamente vinculadas, a distinção entre a origem e o exercício do poder político afastou a teoria política das discussões sobre a democracia, a soberania e o poder constituinte do povo.

No artigo seguinte, "Repensando a mobilização dos direitos humanos - relações entre ativistas e vítimas de violações no caso Alvarado contra o México”, Bruno Boti Bernardi analisa a atuação da organização não governamental (ONG) mexicana Centro de Direitos Humanos das Mulheres (CEDEHM) no caso Alvarado contra o México, perante o sistema interamericano, e mostra que a intermediação desempenhada pelo CEDEHM concede uma posição central para as vítimas e familiares, contribuindo decisivamente para a formação da agência política desses atores e para a politização da própria linguagem dos direitos humanos.

Os direitos humanos são assunto também do terceiro artigo, "Os donos do silêncio: a política externa do regime militar brasileiro e a comissão de direitos humanos das Nações Unidas”, no qual João Roriz revela que, ao contrário do que parte da literatura sobre política externa afirma, a diplomacia brasileira não passou incólume ao aparato repressor do regime militar e teve que mobilizar grandes esforços diplomáticos para enfrentar as acusações de violações de direitos humanos em fóruns internacionais.

No artigo seguinte, “Quien peca y reza empata: tensión entre el discurso universal y las prácticas regionales en la iglesia católica en relación con el neoliberalismo latino-americano", os colombianos Andrés Botero-Bernal, Javier Orlando Aguirre-Román e Juan David Almeyda-Sarmiento exploram as tensões entre o discurso global antineoliberal e as práticas regionais neoliberais dentro da Igreja Católica latino-americana. 
No quinto artigo, "Nuestro Norte es el Sur. a busca da autonomia, os desafios da integração regional e a China", Ingrid Sarti, Marcos Costa Lima e Milton Bragatti oferecem uma análise da trajetória do Mercosul a partir da experiência integracionista do sul na agenda progressista de 2005 a 2015, e refletem sobre os efeitos do ascenso da aproximação chinesa no continente, em franca disputa com os Estados Unidos.

Ainda na região sul do continente americano, Maria Clara Oliveira e Renata Mirandola Bichir contribuem com o artigo "Transferência Monetária no Brasil e no Chile: comparando ideias e o papel de instrument constituencies", discutindo a adoção de políticas disseminadas globalmente. $\mathrm{O}$ artigo demonstra a vantagem de recorrer aos conceitos de comunidade epistêmica e de instrument constituency para examinar não só a disseminação de políticas públicas, mas também para analisar a inserção de problemas na agenda política nacional, a discussão de soluções possíveis e a formulação de políticas públicas a partir do caso empírico das políticas de transferência monetária adotadas no Brasil e no Chile.

No sétimo artigo, "Tecnologias de saber-poder sobre as águas: a experiência do Conselho Mundial da Água”, Rodrigo de Freitas Espinoza e Rodrigo Constante Martins analisam a produção discursiva do Conselho Mundial da Água, criado em 1996 com o objetivo de debater e mobilizar ações internacionais sobre a água, a partir do referencial dos estudos pós-coloniais com a analítica do poder de Michel Foucault e a noção de justificação moral da sociologia pragmática, para compreender os imperativos de discurso no debate internacional sobre meio ambiente.

Em seguida, dois artigos sobre pensamento brasileiro completam este número. No artigo "Um projeto de pesquisa "à esquerda": Gildo Marçal Brandão e a interpretação marxista do pensamento político brasileiro", Christian 
Edward Cyril Lynch e Jorge Gomes de Souza Chaloub oferecem uma análise da trajetória intelectual de Gildo Marçal Brandão (1949-2010), com especial dedicação ao Projeto Temático desenvolvido no CEDEC e no qual buscou delinear as linhagens do Pensamento Político Brasileiro. O artigo sustenta, a partir de abordagem contextualista, que Gildo construiu uma interpretação marxista das tradições políticas brasileiras distinta daquelas deixadas por Wanderley Guilherme dos Santos, de pendor nacionalista, e por Bolívar Lamounier, de índole liberal.

Por fim, este número se encerra com o artigo "Açúcar e café: ambiguidade de Raízes do Brasil', em que Monica Isabel de Moraes e Luiz Carlos Jackson discutem a dimensão política de Raizes do Brasil, por meio de uma reconstrução da trajetória de Sérgio Buarque de Holanda. Os autores argumentam que Sérgio Buarque não fixou em sua obra uma mensagem política unívoca e sugerem que o livro conteria um argumento central com desfecho ambíguo, cuja gênese teria relação com a ambivalência da origem social e geográfica de seu autor.

Todos os nove artigos foram enviados por seus autores ao sistema de submissão da SciELO e receberam uma avaliação positiva dos nossos pareceristas, aos quais muito agradecemos.

\section{Bibliografia}

ANDERSON, Christopher J.; BLAIS, André; BOWLER, Shaun;

DONOVAN, Todd; LISTHAUG, Ola. 2005. Losers' Consent: Elections and

Democratic Legitimacy. Oxford: Oxford University Press.

WEFFORT, Francisco Correa. 1984. Jornais são partidos? Lua Nova, n. 2, pp. 37-40.

WEFFORT, Francisco Correa. 1988. Dilemas da legitimidade política. Lua

Nova, n. 15, pp. 7-30.

WEFFORT, Francisco Correa. 1989. Incertezas da transição na América

Latina. Lua Nova, n. 16, pp. 5-45.

WEFFORT, Francisco Correa. 1990. Editorial. Lua Nova, n. 21, p. 3. 
WEFFORT, Francisco Correa. 1990. A América errada (notas sobre a democracia e a modernidade na América Latina em crise). Lua Nova, n. 21, pp. 5-40.

WEFFORT, Francisco Correa. 1992. Novas democracias. Que democracias? Lua Nova, n. 27, pp. 5-30.

\section{Bruno Konder Comparato}

é professor do Departamento de Ciências Sociais da Universidade Federal de São Paulo (Unifesp). Guarulhos, SP, Brasil.E-mail: bruno.comparato@unifesp.br Orcid: 0000-0001-9356-0362 http://dx.doi.org/10.1590/0102-007016/113 
